\title{
Advancing the science of myocardial recovery with mechanical circulatory support: A Working Group of the National, Heart, Lung, and Blood Institute
}

\author{
Stavros G. Drakos, MD, PhD, ${ }^{a}$ Francis D. Pagani, MD, PhD, ${ }^{b}$ Martha S. Lundberg, $\mathrm{PhD},{ }^{\mathrm{c}}$ and
} Timothy J. Baldwin, $\mathrm{PhD}^{\mathrm{d}}$

\begin{abstract}
The medical burden of heart failure $(\mathrm{HF})$ has spurred interest in clinicians and scientists to develop therapies to restore the function of a failing heart. To advance this agenda, the National Heart, Lung, and Blood Institute (NHLBI) convened a Working Group of experts from June 2 to 3, 2016, in Bethesda, Maryland, to develop NHLBI recommendations aimed at advancing the science of cardiac recovery in the setting of mechanical circulatory support (MCS). MCS devices effectively reduce volume and pressure overload that drives the cycle of progressive myocardial dysfunction, thereby triggering structural and functional reverse remodeling. Research in this field could be innovative in many ways, and the Working Group specifically discussed opportunities associated with genome-phenome systems biology approaches; genetic epidemiology; bioinformatics and precision medicine at the population level; advanced imaging modalities, including molecular and metabolic imaging; and the development of minimally invasive surgical and percutaneous bioengineering approaches. These new avenues of investigations could lead to new treatments that target phylogenetically conserved pathways involved in cardiac reparative mechanisms. A central point that emerged from the NHLBI Working Group meeting was that the lessons learned from the MCS investigational setting can be extrapolated to the broader HF population. With the precedents set by the significant effect of studies of other well-controlled and tractable subsets on larger populations, such as the genetic work in both cancer and cardiovascular disease, the work to improve our understanding of cardiac recovery and resilience in MCS patients could be transformational for the greater HF population. ( $\mathrm{J}$ Thorac Cardiovasc Surg 2017;154:165-70)
\end{abstract}

\footnotetext{
From the ${ }^{\mathrm{a}}$ Division of Cardiovascular Medicine, University of Utah School of Medicine, Salt Lake City, Utah; ' ${ }^{b}$ Division of Cardiac Surgery, University of Michigan School of Medicine, Ann Arbor, Mich; ${ }^{\mathrm{c} A d v a n c e d ~ T e c h n o l o g i e s ~ \& ~ S u r g e r y ~}$ Branch, Division of Cardiovascular Sciences, National Heart, Lung, and Blood Institute, Bethesda, Md; and the ${ }^{\mathrm{d}}$ Advanced Technologies \& Surgery Branch, Basic and Early Translational Research Program, Division of Cardiovascular Sciences, National Heart, Lung, and Blood Institute, Bethesda, Md.

Funding for the Working Group meeting was provided by the National Heart, Lung, and Blood Institute.

This article has been co-published in The Journal of Thoracic and Cardiovascular Surgery, ASAIO Journal, JACC: Basic to Translational Science, and Journal of Cardiac Failure.

S.G.D. and F.D.P. contributed equally to this report

Received for publication Dec 9, 2016; revisions received Feb 28, 2017; accepted for publication March 2, 2017.

Address for reprints: Stavros G. Drakos, MD, PhD, Division of Cardiovascular Medicine, University of Utah School of Medicine, 50 North Medical Dr, Salt Lake City, UT 84132 (E-mail: stavros.drakos@hsc.utah.edu); or Francis D. Pagani, MD, PhD, Division of Cardiac Surgery, University of Michigan School of Medicine, 1500 East Medical Center Drive, SPC 5856, Ann Arbor, MI 48109 (E-mail: fpagani@med.umich.edu). 0022-5223

Copyright (C) 2017 The Authors. Published by Elsevier Inc. on behalf of The American Association for Thoracic Surgery. This is an open access article under the CC BY-NC-ND license (http://creativecommons.org/licenses/by-nc-nd/4.0/).

http://dx.doi.org/10.1016/j.jtcvs.2017.03.033
}

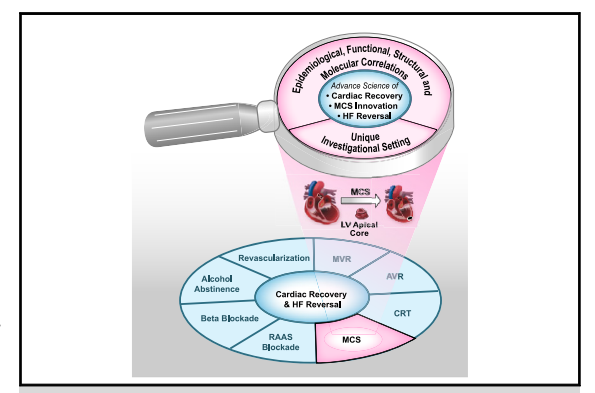

MCS viewed as a "research vehicle" that could help advance the science of cardiac recovery.

\section{Central Message}

The NHLBI convened a Working Group of experts to develop recommendations aimed at advancing the science of cardiac recovery in the setting of MCS and advanced HF

See Editorial Commentary page 171. 
Previously, perceptions held that the heart possessed limited ability to recover in response to significant injury. However, clinical practice has demonstrated important examples of cardiac plasticity (ie, reverse myocardial remodeling) in a variety of clinical scenarios either occurring spontaneously (eg, acute myocarditis) or facilitated through intervention (eg, treatment of tachycardia-induced cardiomyopathy, pharmacologicaldirected therapy, or cardiac resynchronization therapy). ${ }^{2,3}$ With advanced stages of the disease, clinical experience suggests the notion that chronic mechanical unloading of the heart with ventricular assist devices (VADs) can favorably influence the complex process of reverse cardiac remodeling, such that patients placed on longterm MCS can achieve variable degrees of improvement in the structure and function of the native heart along with reversal of the systemic HF phenotype. ${ }^{4-6}$

Excess pressure and volume load drives the cycle of progressive myocardial dysfunction and cardiac remodeling in chronic $\mathrm{HF}^{7}$ VADs provide significant volume and pressure unloading and increased cardiac output, which allows a reversal of stress-related compensatory responses of the overloaded myocardium. As a result, some patients placed on long-term MCS demonstrate reverse cardiac remodeling with restoration of cardiac function, permitting weaning from the MCS device. Table 1 summarizes the results of key clinical outcome studies investigating cardiac functional and structural improvement following long-term MCS therapy (only prospective studies were included). ${ }^{8-20}$ The differences in cardiac recovery rates in these studies likely represents variability in study design, patient selection, and differing acceptable thresholds of cardiac recovery to permit device explantation, as defined by the investigators. Recently, 2 prospective observational studies have reported on the prevalence of cardiac recovery with MCS therapy. The ongoing North American multicenter trial (RESTAGE-HF [Remission From Stage D Heart Failure]) announced promising preliminary results: 12 of $36(33 \%)$ patients with advanced nonischemic dilated cardiomyopathy $(<5$ years of HF history) reached the study pre-defined explant criteria and underwent MCS device explantation. ${ }^{21}$ The primary endpoint of this study is freedom from MCS or

TABLE 1. Prospective studies investigating cardiac functional and structural improvement during chronic left ventricular assist device support

\begin{tabular}{|c|c|c|c|c|c|c|c|}
\hline Group, year, reference & $\mathbf{n}$ & HF etiology & $\begin{array}{l}\text { Adjuvant drug } \\
\text { therapy protocol }\end{array}$ & $\begin{array}{c}\text { Heart } \\
\text { function } \\
\text { monitoring } \\
\text { protocol } \\
\end{array}$ & $\begin{array}{c}\text { LVAD } \\
\text { support } \\
\text { duration (mo) }\end{array}$ & Cardiac recovery* & $\begin{array}{c}\text { Freedom from HF } \\
\text { recurrence after } \\
\text { explantation, follow-up } \\
\text { duration }\end{array}$ \\
\hline $\begin{array}{l}\text { US LVAD Working } \\
\text { Group, } 2007^{8}\end{array}$ & 67 & $\begin{array}{l}\text { NICM: } 55 \% \\
\text { ICM: } 45 \%\end{array}$ & Not standardized & Yes & 4.5 & $\begin{array}{l}\text { NICM: } 13.5 \% \\
\text { ICM: } 3.3 \%\end{array}$ & $100 \%, 6 \mathrm{mo}$ \\
\hline Berlin, 2008 and $2010^{9,10}$ & 188 & NICM: $100 \%$ & Not standardized & Yes & 4 & NICM: $19 \%$ & $\begin{array}{l}74 \% \text { and } 66 \%, 3 \text { and } 5 y, \\
\text { respectively }\end{array}$ \\
\hline $\begin{array}{l}\text { Utah Cardiac Recovery } \\
\text { Program, } 2016^{11}\end{array}$ & 154 & $\begin{array}{l}\text { NICM: } 60 \% \\
\text { ICM: } 40 \%\end{array}$ & Not standardized & Yes & 6 & $\begin{array}{l}\text { NICM: } 21 \% \\
\text { ICM: } 5 \%\end{array}$ & N/A \\
\hline Montefiore, $2013^{12}$ & 21 & $\begin{array}{l}\text { NICM: } 62 \% \\
\text { ICM: } 38 \%\end{array}$ & Yes & Yes & 9 & $\begin{array}{l}\text { NICM: } 23 \% \\
\text { ICM: } 0 \%\end{array}$ & $100 \%, 57 \mathrm{mo}$ \\
\hline Gothenburg, $2006^{13}$ & 18 & $\begin{array}{l}\text { NICM: } 83 \% \\
\text { ICM: } 17 \%\end{array}$ & Not standardized & Yes & 7 & $\begin{array}{l}\text { NICM: } 17 \% \\
\text { ICM: } 0 \%\end{array}$ & $33 \%, 8 y$ \\
\hline Vancouver, $2011^{14}$ & 17 & Not reported & Not standardized & Yes & 7 & NICM and ICM: $23 \%$ & $100 \%, 2 y$ \\
\hline Pittsburgh, $2003^{15}$ & 18 & $\begin{array}{l}\text { NICM: } 72 \% \\
\text { ICM: } 28 \%\end{array}$ & Not standardized & Yes & 8 & $\begin{array}{l}\text { NICM: } 38 \% \\
\text { ICM: } 20 \%\end{array}$ & $67 \%, 16.5 \mathrm{mo}$ \\
\hline $\begin{array}{l}\text { Texas Heart } \\
\text { Institute, } 2003^{16}\end{array}$ & 16 & $\begin{array}{l}\text { NICM: } 75 \% \\
\text { ICM: } 25\end{array}$ & Yes & Yes & 8 & $\begin{array}{l}\text { NICM: } 58 \% \\
\text { ICM: } 50 \%\end{array}$ & $78 \%, 14.3 \mathrm{mo}$ \\
\hline US IMAC, $2012^{17}$ & 14 & NICM: $100 \% \dagger$ & Not standardized & Yes & 3.5 & NICM: $67 \%$ & $87.5 \%, 17.5 \mathrm{mo}$ \\
\hline Harefield, $2006^{18}$ & 15 & NICM: $100 \%$ & Yes & Yes & 11 & NICM: $73 \%$ & $\begin{array}{l}100 \% \text { and } 89 \%, 1 \text { and } 4 y, \\
\text { respectively }\end{array}$ \\
\hline Harefield, $2011^{19}$ & 20 & NICM: $100 \%$ & Yes & Yes & 9 & NICM: $60 \%$ & $83 \%, 3$ y \\
\hline $\begin{array}{l}\text { University of } \\
\text { Athens, } 2007^{20}\end{array}$ & 8 & NICM: $100 \%$ & Yes & Yes & 7 & NICM: $50 \%$ & $100 \%, 2 y$ \\
\hline
\end{tabular}

$\overline{H F}$, Heart failure; $L V A D$, left ventricular assist device; NICM, nonischemic cardiomyopathy; ICM, ischemic cardiomyopathy; N/A, not applicable. * "Cardiac recovery" was defined in all studies but the Utah Cardiac Recovery study as LVAD explantation due to cardiac functional and structural improvement (degree of improvement and specific criteria varied between studies). In the Utah Cardiac Recovery study, ${ }^{11}$ "cardiac recovery" was defined as post-LVAD left ventricular ejection fraction $\geq 40 \%$ in at least 2 consecutive turn-down echocardiograms and no left ventricular ejection fraction $<40 \%$ at later time points (independently of whether the device was eventually explanted). Despite the heterogeneity in the study design, it seems that most programs (Berlin, US LVAD Working Group, Montefiore, Gothenburg, Vancouver, and Utah groups) identified significant cardiac functional and structural improvement in $15 \%$ to $25 \%$ of NICM and $4 \%$ to $5 \%$ of ICM. $\nmid$ The US IMAC (Intervention in Myocarditis and Acute Cardiomyopathy) study group ${ }^{17}$ included only patients with "recent onset cardiomyopathy." 
heart transplantation 1 year post-VAD explant. The trial completed its planned enrollment of 40 patients and expects to announce its full results at the end of 2017. The Utah Cardiac Recovery Program reported on 154 patients with chronic advanced dilated cardiomyopathy supported with a continuous flow left VAD (acute HF was prospectively excluded by study design) and observed an improvement in left ventricular ejection fraction of $\geq 40 \%$ in $21 \%$ of patients with nonischemic cardiomyopathy and $5 \%$ in those with ischemic cardiomyopathy. ${ }^{11}$ Of note, as evident in Table 1, the latter cardiac recovery results in ischemic and nonischemic chronic dilated cardiomyopathy are consistent with earlier conclusions published by the Berlin, US LVAD, Montefiore, Gothenburg, and Vancouver groups. ${ }^{8-14}$

Understanding the mechanisms of cardiac recovery following MCS may be paramount to facilitating cardiac recovery in the broader HF population. Unlike other established medical HF therapies that lead to significant cardiac improvements, MCS therapy offers a unique scientific paradigm to permit studies of the human myocardium from tissue samples obtained both at the time of MCS device implant and following the intervention with MCS at the time of device explant (either due to cardiac recovery or due to heart transplantation) (Figure 1). This special investigational setting provides an unparalleled opportunity to perform in-depth characterizations of recovery signatures at the clinical, physiological, cellular, and molecular levels in humans or

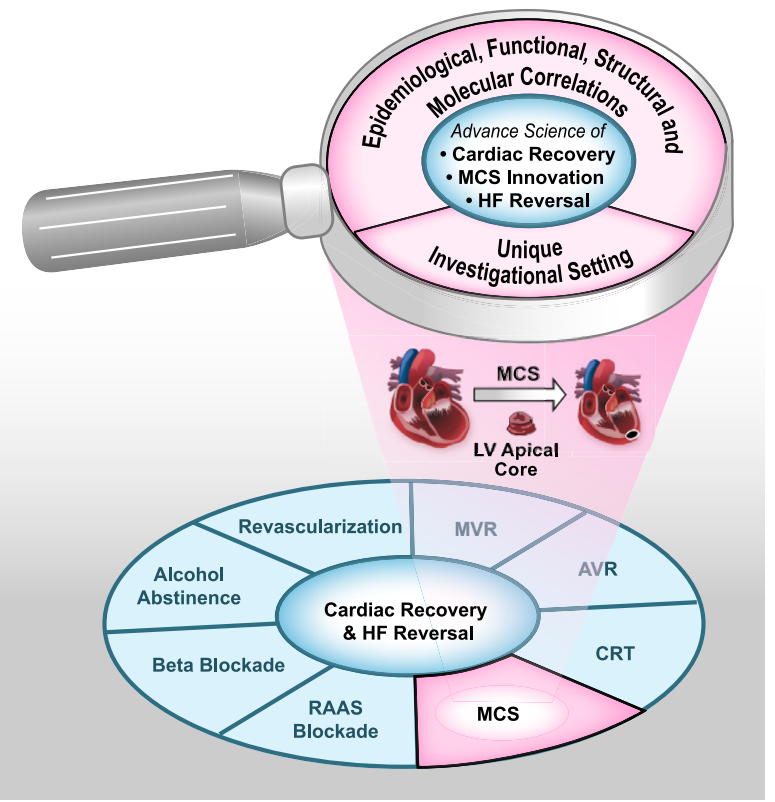

FIGURE 1. The MCS investigational setting is a unique transformative "research vehicle" that could help advance the science of cardiac recovery, HF reversal, and MCS innovation. MCS, Mechanical circulatory support; $H F$, heart failure; $L V$, left ventricle; $M V R$, mitral valve replacement/repair; $A V R$, aortic valve replacement/repair; $C R T$, cardiac resynchronization; $R A A S$, renin-angiotensin-aldosterone system. in animal models designed to simulate the clinical use of MCS devices. As depicted in Figure 1, results from such studies could lead to rational therapeutic approaches to facilitate cardiac recovery in the various etiologies and stages of HF.

The NHLBI Working Group identified a critical shortcoming in the field of cardiac recovery with MCS in that most studies to date have failed to correlate functional outcomes with molecular, cellular, or histological findings. ${ }^{4-6}$ As a result, these earlier studies provide limited information on whether observed biological changes occurring during the period of MCS therapy could be associated with true cardiac recovery mechanisms or alternatively represent epiphenomena related to the MCS therapy, but not directly related to reverse cardiac remodeling. Examination of tissue from patients with various degrees of MCS-induced myocardial functional recovery (ie, "responders") and from MCS patients without functional myocardial improvement (ie, "nonresponders") is critical. Thus, combined functional and biological studies represent a sound approach to begin distinguishing between these 2 scenarios: True mechanistic insights versus epiphenomena. ${ }^{22-29}$ Future, in-depth, investigational steps incorporating a rigorous basic science scientific approach could assign causality and lead to the discovery of novel therapeutic targets.

Extrapolating the lessons learned from the MCS investigational setting to the broader HF population was a central point that emerged from the NHLBI Working Group meeting (Figure 1). With the precedents set by the significant effect of studies of other well-controlled and tractable subsets on larger populations, such as the genetic work in both cancer and cardiovascular disease, ${ }^{30-33}$ the work to improve our understanding of cardiac recovery and resilience in MCS patients could be transformational for the greater HF population (Figure 1). Research in this field could be innovative in many ways, and Working Group members specifically discussed opportunities associated with genome-phenome systems biology approaches; genetic epidemiology; bioinformatics and precision medicine at the population level; advanced imaging modalities, including molecular and metabolic imaging; and minimally invasive surgical and percutaneous bioengineering approaches. These new avenues of investigations could lead to new treatments that target phylogenetically conserved pathways involved in cardiac reparative mechanisms rather than perpetuating current approaches of targeting pathways that attenuate adverse remodeling. ${ }^{3}$ They also have the potential to change the paradigm in the treatment of chronic HF from one of attenuation of adverse cardiac remodeling to induction of self-repair mechanisms in specific patient populations, and to revise the existing dogma that severe HF requiring MCS support always indicates end-stage, nonreversible, 
myocardial disease. ${ }^{34-36}$ With these possibilities in mind, the Working Group made the following recommendations (and specific examples for each) to the NHLBI regarding areas of need and opportunity in the science and engineering of cardiac recovery associated with $\mathrm{MCS}^{37}$ :

1. Explore mechanistic approaches at the genetic, molecular, cellular, microstructural, or physiological level to improve the understanding of myocardial recovery and develop novel interventions.

a. Assess the incidence, completeness, and sustainability of recovery using integrated physiology.

b. Determine and exploit the mechanistic link between alterations in MCS pressure-volume loading profiles associated with myocardial recovery (ie, identify and optimize biomechanical loading regimens that predict or contribute to sustained myocardial recovery).

c. Develop methodologies to follow and optimize sustained recovery in post-explant patients, including novel imaging and sensor technologies.

d. Identify associations between molecular, hematological, and/or biochemical markers and hemodynamic/ clinical parameters that: (1) define clinical recovery; or (2) define maladaptive consequences during MCS.

e. Interrogate genetic/genomic responses in recovery that may be relevant to the broader HF population.

2. Utilize epidemiological approaches and populationbased studies to identify the associative host factors and MCS device characteristics that influence the incidence and degree of myocardial recovery associated with MCS.

a. Distinguish between favorable and unfavorable host factors that affect recovery with MCS (ie, age, sex, genetics, disease state, duration of HF, and so on).

b. Identify the biological and clinical determinants of the degree and sustainability of recovery.

c. Assess the degree and sustainability of recovery in HF populations receiving MCS and non-MCS interventions.

d. Determine favorable and unfavorable device characteristics or clinical events related to devices that influence myocardial recovery (eg, unloading characteristics, flow characteristics, the effect of MCS adverse events on recovery, and understanding MCS effects on the cardiovascular system to reduce them).

3. Leverage innovative strategies and approaches to investigate the science and engineering of myocardial recovery with MCS.

a. Develop appropriate animal models for targeted mechanistic studies of myocardial recovery. b. Develop objective measures of unloading and reloading of myocardium using advanced imaging modalities and sensors, metabolic techniques, and physiological data.

c. Develop novel MCS device designs and control strategies that could enhance myocardial recovery.

d. Develop a bio-repository to implement high priority recommendations.

e. Leverage existing networks (ie, data sources such as clinical registries) to implement translational and/or clinical studies of recovery.

f. Develop specialized expertise and infrastructure for pre-clinical testing of novel adjunctive therapies to promote myocardial recovery.

g. Translate novel adjuvant interventions (shown in pre-clinical studies or human lab-based studies to enhance recovery) into clinical therapies through randomized clinical trials or other novel adaptive trial designs.

The previously mentioned recommendations tie very well with the NHLBI objectives, as described in the recently released new NHLBI strategic vision, ${ }^{38}$ and especially understanding resilience, identifying factors that account for individual differences in pathobiology and in responses to treatment, and developing and optimizing novel therapeutic strategies to treat and cure disease. The Working Group also recommended inclusion of both adult and pediatric populations. Future research efforts may also include patient-reported outcomes and cost data to allow for study of interventions aimed at recovery on quality-of-life and cost-effectiveness.

Finally, the Working Group also developed the following working definition of cardiac recovery: "A reversal of the pathological state of the myocardium with significant improvement in cardiac structure and function sufficient to achieve a sustained remission from recurrent heart failure events."

\section{PARTICIPANTS IN THE NHLBI WORKING GROUP}

NHLBI Contact: J. Timothy Baldwin, PhD, NHLBI, National Institutes of Health.

Chairs: Stavros G. Drakos, MD, University of Utah Hospitals and Clinics; and Francis D. Pagani, MD, PhD, University of Michigan Medical Center.

Members: E. Dale Abel, MD, PhD, University of Iowa Carver College of Medicine; Michael A. Acker, MD, University of Pennsylvania Perelman School of Medicine; Emma J. Birks, MD, PhD, University of Louisville Jewish Hospital; Daniel Burkhoff, MD, PhD, Cardiovascular Research Foundation; Michael Dandel, MD, PhD, German Heart Institute, Berlin; David J. Farrar, PhD, St. Jude Medical, Inc.; Julius Guccione, PhD, University of California, San Francisco; Ray E. Hershberger, MD, Ohio 
State University; John L. Jefferies, MD, Cincinnati Children's Hospital; James K. Kirklin, MD, University of Alabama at Birmingham; Stephen C. Koenig, PhD, University of Louisville; Dean Y. Li, MD, PhD, University of Utah School of Medicine; Douglas L. Mann, MD, Washington University School of Medicine; Kenneth B. Margulies, MD, University of Pennsylvania Perelman School of Medicine; Mandeep R. Mehra, MD, Brigham \& Women's Hospital; Ivan Netuka, MD, PhD, Charles University, Prague; Linda R. Peterson, MD, Washington University School of Medicine; J. Eduardo Rame, MD, University of Pennsylvania Perelman School of Medicine; Russell S. Richardson, PhD, University of Utah School of Medicine; Joseph G. Rogers, MD, Duke University School of Medicine; Hesham Sadek, MD, PhD, University of Texas Southwestern Medical Center; Stephan Schueler, MD, PhD, Newcastle Upon Tyne Freeman Hospital; Craig H. Selzman, MD, University of Utah Hospitals and Clinics; Francis G. Spinale, MD, PhD, University of South Carolina School of Medicine; Veli K. Topkara, MD, Columbia University Medical Center; Nir Uriel, MD, University of Chicago Medicine Center; John T. Watson, PhD, University of California, San Diego; Matthew T. Wheeler, MD, Stanford University School of Medicine

NHLBI Program Staff: Catherine D. Burke, MA, Martha S. Lundberg, PhD, Marissa A. Miller, DVM, MPH.

\section{APPENDIX}

For supplemental tables, please see the online version of this article.

\section{Conflict of Interest Statement}

Authors have nothing to disclose with regard to commercial support. The views expressed in this article are those of the authors and do not necessarily represent those of the National Institutes of Health or the US Department of Health and Human Services.

\section{References}

1. Mozaffarian D, Benjamin EJ, Go AS, Arnett DK, Blaha MJ, Cushman M, et al, on behalf of the American Heart Association Statistics Committee and Stroke Statistics Subcommittee. Heart disease and stroke statistics-2016 update: a report from the American Heart Association. Circulation. 2016;133: e38-360.

2. Hellawell JL, Margulies KB. Myocardial reverse remodeling. Cardiovasc Ther. 2012;20:172-81.

3. Mann DL, Barger PM, Burkhoff D. Myocardial recovery and the failing heart: myth, magic or molecular target? J Am Coll Cardiol. 2012;60:2465-72.

4. Drakos SG, Kfoury AG, Stehlik J, Selzman CH, Reid BB, Terrovitis JV, et al. Bridge to recovery: understanding the disconnect between clinical and biological outcomes. Circulation. 2012;126:230-41.

5. Hall JL, Fermin DR, Birks EJ, Barton PJ, Slaughter M, Eckman P, et al. Clinical, molecular, and genomic changes in response to a left ventricular assist device. $J$ Am Coll Cardiol. 2011;57:641-52.

6. Drakos SG, Mehra MR. Clinical myocardial recovery during long-term mechanical support in advanced heart failure: insights into moving the field forward. $J$ Heart Lung Transplant. 2016;35:413-20.
7. Katz AM. Maladaptive growth in the failing heart: the cardiomyopathy of overload. Cardiovasc Drugs Ther. 2002;16:245-9.

8. Maybaum S, Mancini D, Xydas S, Starling RC, Aaronson K, Pagani FD, et al Cardiac improvement during mechanical circulatory support: a prospective multicenter study of the LVAD working group. Circulation. 2007;115:2497-505.

9. Dandel M, Weng Y, Siniawski H, Potapov E, Drews T, Lehmkuhl HB, et al Prediction of cardiac stability after weaning from left ventricular assist devices in patients with idiopathic dilated cardiomyopathy. Circulation. 2008;118: S94-105.

10. Dandel M, Weng Y, Siniawski H, Stepanenko A, Krabatsch T, Potapov E, et al Heart failure reversal by ventricular unloading in patients with chronic cardiomyopathy: criteria for weaning from ventricular assist devices. Eur Heart J. 2011;32: 1148-60.

11. Wever-Pinzon J, Selzman CH, Wever-Pinzon O, Catino A, Kfoury AG, Stehlik J, et al. Impact of ischemic heart failure etiology on the incidence of cardiac recovery during mechanical unloading: a prospective study from the Utah Cardiac Recovery Program. J Am Coll Cardiol. 2016;68: $1741-52$.

12. Patel SR, Saeed O, Murthy S, Bhatia V, Shin JJ, Wang D, et al. Combining neurohormonal blockade with continuous-flow left ventricular assist device support for myocardial recovery: a single-arm prospective study. J Heart Lung Transplant. 2013;32:305-12.

13. Liden H, Karason K, Bergh CH, Nilsson F, Koul B, Wiklund L. The feasibility of left ventricular mechanical support as a bridge to cardiac recovery. Eur J Heart Fail. 2007;9:525-30

14. Lamarche Y, Kearns M, Josan K, Bashir J, Ignaszewski A, Kaan A, et al. Successful weaning and explantation of the Heartmate II left ventricular assist device. Can J Cardiol. 2011;27:358-62.

15. Gorcsan J III, Severyn D, Murali S, Kormos RL. Non-invasive assessment of myocardial recovery on chronic left ventricular assist device: results associated with successful device removal. J Heart Lung Transplant. 2003;22:1304-13.

16. Khan T, Delgado RM, Radovancevic B, Torre-Amione G, Abrams J, Miller K, et al. Dobutamine stress echocardiography predicts myocardial improvement in patients supported by left ventricular assist devices (LVADs): hemodynamic and histologic evidence of improvement before LVAD explantation. J Heart Lung Transplant. 2003;22:137-46.

17. Boehmer JP, Starling RC, Cooper LT, Torre-Amione G, Wittstein I, Dec GW, et al, for the IMAC Investigators. Left ventricular assist device support and myocardial recovery in recent onset cardiomyopathy. J Card Fail. 2012;18:755-61.

18. Birks EJ, Tansley PD, Hardy J, George RS, Bowles CT, Burke M, et al. Left ventricular assist device and drug therapy for the reversal of heart failure. $N$ Engl J Med. 2006;355:1873-84.

19. Birks EJ, George RS, Hedger M, Bahrami T, Wilton P, Bowles CT, et al Reversal of severe heart failure with a continuous-flow left ventricular assist device and pharmacological therapy: a prospective study. Circulation. 2011; 123:381-90

20. Drakos SG, Terrovitis JV, Anastasiou-Nana MI, Nanas JN. Reverse remodeling during long-term mechanical unloading of the left ventricle. J Mol Cell Cardiol. 2007;43:231-42.

21. Birks EJ, Rame E, Patel S, Selzman C, Cunningham C, Um J, et al. Remission from Stage D Heart Failure (RESTAGE-HF): a prospective multi-center non-randomized study of myocardial recovery using LVADs [abstract]. Circulation. 2016;134:A19838.

22. Terracciano CM, Hardy J, Birks EJ, Khaghani A, Banner NR, Yacoub MH. Clinical recovery from end-stage heart failure using left- ventricular assist device and pharmacological therapy correlates with increased sarcoplasmic reticulum calcium content but not with regression of cellular hypertrophy. Circulation 2004; 109:2263-5.

23. Cullen ME, Yuen AH, Felkin LE, Smolenski RT, Hall JL, Grindle S, et al Myocardial expression of the arginine:glycine amidinotransferase gene is elevated in heart failure and normalized after recovery: potential implications for local creatine synthesis. Circulation. 2006;114:I16-20.

24. Hall JL, Birks EJ, Grindle S, Cullen ME, Barton PJ, Rider JE, et al. Molecular signature of recovery following combination left ventricular assist device (LVAD) support and pharmacologic therapy. Eur Heart J. 2007;28:613-27.

25. Drakos SG, Athanasoulis T, Malliaras KG, Terrovitis JV, Diakos N Koudoumas D, et al. Myocardial sympathetic innervation and long-term left ventricular mechanical unloading. JACC Cardiovasc Imaging. 2010;3:64-70.

26. Birks EJ, Hall JL, Barton PJ, Grindle S, Latif N, Hardy JP, et al. Gene profiling changes in cytoskeletal proteins during clinical recovery after left ventricularassist device support. Circulation. 2005;112:157-64. 
27. Diakos NA, Selzman CH, Sachse FB, Stehlik J, Kfoury AG, Wever-Pinzon O, et al. Myocardial atrophy and chronic mechanical unloading of the failing human heart: implications for cardiac assist device-induced myocardial recovery. J Am Coll Cardiol. 2014;64:1602-12.

28. Ramani R, Vela D, Segura A, McNamara D, Lemster B, Samarendra V, et al. A micro-ribonucleic acid signature associated with recovery from assist device support in 2 groups of patients with severe heart failure. J Am Coll Cardiol. 2011;58: 2270-8.

29. Diakos NA, Navankasattusas S, Abel ED, Rutter J, McCreath L, Ferrin P, et al. Evidence of glycolysis upregulation and pyruvate mitochondrial oxidation mismatch during mechanical unloading of the failing human heart: implications for cardiac reloading and conditioning. JACC Basic Transl Sci. 2016;1:432-44.

30. Futreal PA, Liu Q, Shattuck-Eidens D, Cochran C, Harshman K, Tavtigian S, et al. BRCA1 mutations in primary breast and ovarian carcinomas. Science. 1994;266:120-2.

31. Miki Y, Swensen J, Shattuck-Eidens D, Futreal PA, Harshman K, Tavtigian S, et al. A strong candidate for the breast and ovarian cancer susceptibility gene BRCA1. Science. 1994;266:66-71.

32. Goldgar DE, Cannon-Albright LA, Oliphant A, Ward JH, Linker G, Swensen J, et al. Chromosome 17q linkage studies of 18 Utah breast cancer kindreds. Am J Hum Genet. 1993;52:743-8.
33. Keating M, Atkinson D, Dunn C, Timothy K, Vincent GM, Leppert M. Linkage of a cardiac arrhythmia, the long QT syndrome, and the Harvey ras-1 gene. Science. 1991;252:704-6.

34. Selzman CH, Madden JL, Healy AH, McKellar SH, Koliopoulou A, Stehlik J, et al. Bridge to removal: a paradigm shift for left ventricular assist device therapy. Ann Thorac Surg. 2015;99:360-7.

35. Drakos SG, Wever-Pinzon O, Selzman CH, Gilbert EM, Alharethi R, Reid BB, et al. Magnitude and time course of changes induced by continuous-flow left ventricular assist device unloading in chronic heart failure: insights into cardiac recovery. J Am Coll Cardiol. 2013;61: 1985-94.

36. Wever-Pinzon O, Drakos SG, McKellar SH, Horne BD, Caine W, Kfoury AG, et al. Cardiac recovery during long-term left ventricular assist device support. J Am Coll Cardiol. 2016;68:1540-53.

37. NHLBI Working Group on Advancing the Science of Myocardial Recovery with Mechanical Circulatory Support - Executive Summary. Available at: http://www.nhlbi.nih.gov/research/reports/nhlbi-working-group-advancingscience-myocardial-recovery-mechanical-circulatory-support. Accessed April 8, 2017.

38. The NHLBI's Strategic Vision rests on four mission-driven goals that will benefit from sustained Institute focus. Available at: http://www.nhlbi.nih.gov/about/ documents/strategic-vision. Accessed April 8, 2017. 